\title{
Study of menstrual pattern changes in patients accepting injection depo-medroxyprogesterone acetate versus levonorgestrel intrauterine system
}

\author{
Saloni Jain*, Poonam Mani, \\ Department of Obstetrics and. Gynecology, Subharti Medical College, Meerut, Uttar Pradesh, India
}

\author{
Received: 07 December 2020 \\ Revised: 08 January 2021 \\ Accepted: 12 January 2021 \\ *Correspondence: \\ Dr. Saloni Jain, \\ E-mail: intsaloni.012@gmail.com
}

Copyright: () the author(s), publisher and licensee Medip Academy. This is an open-access article distributed under the terms of the Creative Commons Attribution Non-Commercial License, which permits unrestricted non-commercial use, distribution, and reproduction in any medium, provided the original work is properly cited.

\begin{abstract}
Background: Changes in menstrual bleeding patterns are a major cause of hormonal contraceptive discontinuation. DMPA and LNG IUS both are hormonal contraceptives and are used by most of the women worldwide for various gynaecological conditions. The aim of the present study was to compare menstrual pattern changes in patients accepting injection DMPA and LNG-IUS for various gynaecological indications.

Methods: This randomized controlled trial was conducted among 70 women aged 18 years or older with heavy menstrual bleeding in the department of Obstetrics and Gynaecology, Chhatrapati Shivaji Subharti Medical College, Meerut. The study comprised of two groups having 35 patients each i.e. Group 1 (patient who opted for LNG IUS) and Group 2 (patient who opted injection DMPA). The menstrual pattern changes were assessed at 1month, 3month and 6th month interval. Patient were asked to maintain a menstrual calendar wherein she would keep a record of the no. of days along with dates when she has spotting per vaginum/bleeding per vaginum and the amount of blood loss explained to her through the pictorial blood assessment chart.

Results: Reduction in median menstrual blood loss was significantly greater in the LNG IUS group (-128.12 ml, range -393.6 to $328.5 \mathrm{ml}$ ) than in the DMPA group arm $-17.8 \mathrm{ml}$, range -271.5 to+78.6 $\mathrm{ml}, \mathrm{p}<0.001$ ).
\end{abstract}

Conclusions: LNG IUS reduces menstrual blood loss more effectively than DMPA.

Keywords: DMPA, LNG-IUS, Menstrual changes

\section{INTRODUCTION}

Menstrual disorders are common gynaecological problem for medical visits among women of reproductive age. ${ }^{1}$ Heavy menstrual bleeding affects up to $30 \%$ of women in their reproductive period. ${ }^{2}$ In the United States, more than 600,000 hysterectomies are performed annually., Approximately $90 \%$ of these were for benign diseases including menstrual disorders (approximately $17 \%$ of the total number of hysterectomies) such as heavy menstrual bleeding. Heavy menstrual bleeding, defined objectively as blood loss $80 \mathrm{~mL}$ or more per menstrual cycle, is an important cause of iron-deficiency anemia and adversely affects health-related quality of life. ${ }^{5}$

Although hysterectomy or endometrial ablation provides effective surgical options for heavy menstrual bleeding, both approaches are associated with perioperative and long-term surgical risks. Algorithms for heavy menstrual bleeding emphasize the use of medical treatment before resorting to surgical options. Hormonal therapies including oral contraceptive pills, progestogen, danazol, GnRHa and gestrinone had been shown to be equally effective. ${ }^{6,7}$ 
For reasons of the side-effects, therapies such as danazol and GnRHa are limited to six months' usage. On the contrary, depot medroxyprogesterone acetate (MPA) can be applied for a long duration. In addition to reduction in endometriosis-associated pain, it is useful to shrink small endometriotic deposits. The levonorgestrel-releasing intrauterine system (LNGIUS) is another mode of progestin administration. It has been shown in a previous pilot study as useful to reduce endometriosis-associated pain. $^{8}$

A recent small, short-term, randomized trial assessed the efficacy of MPA ( $5 \mathrm{mg}$ daily, every day starting on the first day of the cycle), and LNGIUS in reducing bleeding in a population of older reproductive- aged women with heavy menstrual bleeding. This report found that, although each of the treatments significantly reduced menstrual blood loss and the efficacy of the levonorgestrel-releasing intrauterine system was superior to MPA. ${ }^{9}$

But there is scarce literature available on the same, especially in Indian setting. Hence the present study was conducted to assess the efficacy and safety of the levonorgestrel-releasing intrauterine system and injection medroxyprogesterone acetate for the treatment of heavy menstrual bleeding among women who choose to use intrauterine contraception.

\section{METHODS}

This was a multicenter, randomized, open-label, parallelgroup, active-control study attending gynecological OPD of Subharti Medical College, Meerut, over a period of two years (September 2018 to September 2020). The study protocol for all procedures was approved by the Institutional Review Board for Ethical Clearance of the institution and was performed in accordance with the Code of Ethics of the World Medical Association according to the Declaration of Helsinki of 1975, as revised in 2000. All patients were asked to sign a written consent form prior to commencement of the study. The subjects were selected according to the following inclusion and exclusion criteria:

\section{Inclusion criteria}

Parous women aged 18 years or older with idiopathic heavy menstrual bleeding (menstrual blood loss $80 \mathrm{~mL}$ or more per cycle) desiring intrauterine contraception and willing to use barrier contraception if required were considered for participation in this study.

\section{Exclusion criteria}

Included changes in menstrual regularity, hot flushes, sleeping disorders, or changes in mood within the 3 months preceding the study; breastfeeding; congenital or acquired uterine abnormality, including fibroids if they distorted the uterine cavity or cervical canal (three or more subserous or intramural fibroids with a total volume of less than $5 \mathrm{~cm}^{3}$ were acceptable); history of organic causes of abnormal uterine bleeding (eg, endometriosis, adenomyosis, endometrial polyps); use of the levonorgestrel-releasing intrauterine system or a copper intrauterine device during the 30 days before the study; history of vascular or coagulation disorders; concomitant use of medication or presence of an underlying disease/condition known to affect the metabolism or pharmacokinetics of the study medication; and a body mass index greater than $35 \mathrm{~kg} / \mathrm{m}^{2}$.

\section{Sample size}

This calculator uses the following formula for the sample size n:

$\mathrm{N}=(\mathrm{Z} \alpha / 2)^{2} \mathrm{~s}^{2} / \mathrm{d}^{2 *} 100$

Where $\mathrm{N}$ denotes sample size, $\mathrm{s}$ is the difference in standard deviation obtained from previous study and $\mathrm{d}$ is the accuracy of estimate or difference between the two means. $Z \alpha / 2$ is normal deviate for two- tailed alternative hypothesis at a level of significance.

\section{Calculations}

$\mathrm{S}=0.2$ (From previous study), Z@/2=1.96 at type 1 error of $5 \%, d=0.7$

$$
\mathrm{N}=(1.96)^{2} 0.22 / 0.72 * 100=31.35
$$

Considering the error and drop out of $10 \%$, the sample size will be increased to 35. As the present study comprised of two groups, therefore the sample size required per group for the present study will be 35 .

Menstrual blood loss of $80 \mathrm{~mL}$ or more per cycle was confirmed in at least two screening menstrual cycles before the participants were randomized in a 1:1 ratio to receive treatment with either the levonorgestrel-releasing intrauterine system or injection medroxyprogesterone acetate.

\section{Procedure}

Women randomly assigned to the levonorgestrel releasing intrauterine system had the system placed within 7 days of the onset of menstruation (in case of initial placement failure, only one attempt at replacement could be made). Those randomly assigned to injectable medroxyprogesterone acetate received $10 \mathrm{mg}$ of the drug once daily for 10 consecutive days in each cycle (the highest dose and regimen indicated in the current label for the treatment of abnormal uterine bleeding attributable to hormonal imbalance in the absence of organic pathology), starting on day 16 of their menstrual cycle. 
All women were given diary cards to record menstrual bleeding on a daily basis. Those women on the injectable medroxyprogesterone acetate group also used the diary cards to record tablet intake (along with the return of unused treatment packs) so that treatment adherence could be monitored. All participants were provided dedicated containers and instructed to collect all used sanitary protection during cycles three and six to assess menstrual blood loss (as performed in the screening phase).

The day on which the levonorgestrel-releasing intrauterine system was placed was considered the first day of cycle 1 , and each cycle was considered to last for 30 days. In the injectable medroxyprogesterone acetate group, each menstrual cycle was considered to start on the first day of menstrual bleeding and last until the last nonbleeding day before the onset of the next bleeding episode. Safety evaluation included clinical assessments (physical and gynecologic examinations), monitoring of adverse events and changes in laboratory values for hematological, serum chemistry, and urinalysis variables.

All adverse events (observed, volunteered, and solicited) were coded using MedDRA (the Medical Dictionary for Regulatory Activities (MedDRA) is the international medical terminology developed under the auspices of the International Conference.

At the end of the study, women randomly assigned to medroxyprogesterone acetate were able to select using the levonorgestrel-releasing intrauterine system if they desired one. Likewise, those allocated to the levonorgestrel-releasing intrauterine system were allowed to continue its use.

The two primary efficacy variables were the absolute change in menstrual blood loss from baseline to the end of the study and the proportion of those in which the treatment was successful (defined as menstrual blood loss less than $80 \mathrm{~mL}$ at end of study and $50 \%$ or greater reduction in menstrual blood loss from baseline).

\section{Statistical analysis}

The data was collected and subjected to statistical analysis using SPSS software version 23. Difference between two groups was determined using student t-test and the level of significance was set at $\mathrm{p}<0.05$.

\section{RESULTS}

The mean \pm SD age (in years), BMI $\left(\mathrm{kg} / \mathrm{m}^{2}\right)$ and cycle length was $38.1 \pm 4.8,26.8 \pm 3.2,2.2(1-4)$ and 38.8 \pm 5.1 , 27.3 $\pm 3.7,2.4$ (1-5) in LNG-IUS and injectable DMPA group respectively (Table 1$)$.

Table 2, 3 summarizes the menstrual blood loss parameters for both treatment groups. Levonorgestrelreleasing intrauterine system users experienced significantly greater absolute reductions in mean menstrual blood loss than participants using medroxyprogesterone acetate at midstudy $(-110.17 \mathrm{~mL}$ compared with $-34.13 \mathrm{~mL} ; \mathrm{p}<0.01)$ and end of study ($118.12 \mathrm{~mL}$ compared with $-42.49 \mathrm{~mL} ; \mathrm{p}<0.01)$.

Table 1: Baseline characteristics of the study groups.

\begin{tabular}{|lll|}
\hline Variables & $\begin{array}{l}\text { LNG-IUS } \\
(\mathbf{n = 3 5})\end{array}$ & $\begin{array}{l}\text { Injectable } \\
\text { DMPA }(\mathbf{n = 3 5})\end{array}$ \\
\hline $\begin{array}{l}\text { Age in years } \\
\text { (Mean } \pm \text { SD) }\end{array}$ & $38.1 \pm 4.8$ & $38.8 \pm 5.1$ \\
\hline $\begin{array}{l}\text { BMI, kg/m } \\
\text { (Mean } \pm \text { SD) }\end{array}$ & $26.8 \pm 3.2$ & $27.3 \pm 3.7$ \\
\hline $\begin{array}{l}\text { Mean cycle length } \\
\text { (Mean, Range) }\end{array}$ & $2.2(1-4)$ & $2.4(1-5)$ \\
\hline
\end{tabular}

Table 2: Comparison of menstrual blood loss parameters among the study groups at 0,3 and 6 months.

\begin{tabular}{|llll|}
\hline Variables & LNG-IUS $(\mathbf{n}=35)$ & Injectable DMPA $(\mathbf{n}=35)$ & P value \\
\hline Median menstrual blood loss, $\mathbf{m l}$ & & & 0.71 \\
\hline 0 month (range) & $150.24(66.1-440.9)$ & $153.8(66.1-451.4)$ & $<0.01 *$ \\
\hline 3 months (range) & $34.1(0-299.2)$ & $124.11(0-389.2)$ & $<0.01 *$ \\
\hline 6 months (range) & $7.4(0-311.4)$ & $115.18(0-399.3)$ & \\
\hline
\end{tabular}

*Statistically significant

Table 3: Mean and median change of menstrual blood loss parameters among the study groups at 3 and 6 months.

\begin{tabular}{|llll|}
\hline Variables & LNG-IUS $(\mathbf{n = 3 5})$ & Injectable DMPA (n=35) & P value \\
\hline Mean Change, $\mathbf{m l}$ & & & \\
\hline At 3 months $(\mathbf{9 5 \%}$ CI) & $-110.17(-126.2$ to -96.6$)$ & $-34.13(-49.1$ to -3.2$)$ & $<0.01^{*}$ \\
\hline At 6 months & $-118.12(-138.11$ to -101.8$)$ & $-42.49(-71.28$ to -8.7$)$ & $<0.01^{*}$ \\
\hline Median Change at 6 months of study, $\mathbf{m L}$ & $-128.12(-393.6$ to 328.5$)$ & $-17.8(-271.5$ to 78.6$)$ & $<0.01^{*}$ \\
\hline
\end{tabular}

*Statistically significant 
No deaths or drug-related serious adverse event occurred during the study. Overall complications were reported more in LNG-IUS group as compared to injectable DMPA group as shown in Table 4 and 5.

Table 4: Comparison of adverse events reported during the study among the groups at $\mathbf{0}$ month.

\begin{tabular}{|c|c|c|c|c|}
\hline \multirow[t]{2}{*}{ Variables } & \multicolumn{2}{|c|}{$\begin{array}{l}\text { LNG-IUS } \\
(\mathbf{n}=35)\end{array}$} & \multicolumn{2}{|c|}{$\begin{array}{l}\text { Injectable } \\
\text { DMPA } \\
(\mathbf{n}=35)\end{array}$} \\
\hline & $\mathbf{N}$ & $\%$ & $\mathbf{N}$ & $\%$ \\
\hline Headache & 9 & 25.71 & 6 & 17.14 \\
\hline $\begin{array}{l}\text { Vaginitis } \\
\text { (bacterial) }\end{array}$ & 6 & 17.14 & 2 & 5.71 \\
\hline $\begin{array}{l}\text { Urinary tract } \\
\text { infection }\end{array}$ & 4 & 11.43 & 2 & 5.71 \\
\hline Acne & 3 & 8.57 & 3 & 8.57 \\
\hline Hypertension & 4 & 11.43 & 1 & 2.86 \\
\hline Sinusitis & 3 & 8.57 & 1 & 2.86 \\
\hline $\begin{array}{l}\text { Upper respiratory } \\
\text { tract infection }\end{array}$ & 3 & 8.57 & 2 & 5.71 \\
\hline Breast tenderness & 2 & 5.71 & 1 & 2.86 \\
\hline Fatigue & 2 & 5.71 & 1 & 2.86 \\
\hline Pelvic pain & 2 & 5.71 & 1 & 2.86 \\
\hline Increased weight & 2 & 5.71 & 3 & 8.57 \\
\hline $\begin{array}{l}\text { Lower abdominal } \\
\text { pain }\end{array}$ & 2 & 5.71 & 3 & 8.57 \\
\hline
\end{tabular}

Table 5: Comparison of adverse events reported during the study among the groups at 3 month.

\begin{tabular}{|lllll|}
\hline \multirow{2}{*}{ Variables } & \multicolumn{2}{l}{$\begin{array}{l}\text { LNG-IUS } \\
(\mathbf{n}=35)\end{array}$} & \multicolumn{2}{l|}{$\begin{array}{l}\text { Injectable } \\
\text { DMPA }(\mathbf{n}=35)\end{array}$} \\
\hline N & \% & $\mathbf{N}$ & \% \\
\hline Headache & 1 & 2.86 & 0 & 0 \\
\hline Vaginitis (bacterial) & 0 & 0 & 0 & 0 \\
\hline $\begin{array}{l}\text { Urinary tract } \\
\text { infection }\end{array}$ & 1 & 2.86 & 0 & 0 \\
\hline Acne & 0 & 0 & 0 & 0 \\
\hline Hypertension & 0 & 0 & 0 & 0 \\
\hline Sinusitis & 0 & 0 & 0 & 0 \\
\hline $\begin{array}{l}\text { Upper respiratory } \\
\text { tract infection }\end{array}$ & 0 & 0 & 0 & 0 \\
\hline Breast tenderness & 0 & 0 & 0 & 0 \\
\hline Fatigue & 0 & 0 & 0 & 0 \\
\hline Pelvic pain & 0 & 0 & 0 & 0 \\
\hline Increased weight & 0 & 0 & 0 & 0 \\
\hline $\begin{array}{l}\text { Lower abdominal } \\
\text { pain }\end{array}$ & 0 & 0 & 1 & 2.86 \\
\hline
\end{tabular}

\section{DISCUSSION}

Compared with medroxyprogesterone acetate, treatment with the levonorgestrel-releasing intrauterine system resulted in greater reductions in menstrual blood loss and therefore higher likelihood of treatment success. Our results are similar to those of previous studies using the alkaline hematin method to assess blood loss in women using the levonorgestrel-releasing intrauterine system.

In our study, mean reduction in menstrual blood was comparatively less in DMPA group as compared to previous studies. Superior results with cyclical oral medroxyprogesterone acetate (assessed with the alkaline hematin method) have been reported using $10 \mathrm{mg}$ three times daily from day 5 to 25 for ovulatory women (49\% decrease) or day 12 to 25 for anovulatory women (36\% decrease). ${ }^{10}$ An even greater mean reduction (57\%) in menstrual blood loss after 3 months was achieved with oral medroxyprogesterone acetate $(10 \mathrm{mg}$ twice daily from day 5 to day 25 of the cycle) in another study that used pictorial blood loss assessment chart scores. ${ }^{11}$

The higher efficacy with oral medroxyprogesterone acetate observed in the other studies may be attributed, in part, to the higher progestin dose and longer treatment duration per cycle compared with our study. ${ }^{12}$ Although a higher dose and longer duration of treatment may have improved results with medroxyprogesterone acetate, it is not likely that the treatment would have been superior to the more than $70 \%$ reduction observed with the levonorgestrel releasing intrauterine system.

The reduction in menstrual blood loss with the levonorgestrel-releasing intrauterine system has been shown to be greater than with oral nonsteroidal antiinflammatory agents, tranexamic acid, or a combination estrogen-progestin oral contraceptive. ${ }^{13,14}$ Although a randomized trial found that the median reduction in menstrual blood loss was not significantly different over three cycles between the levonorgestrelreleasing intrauterine system and norethindrone $(5 \mathrm{mg}$ three times daily from day 5 to 26 ), more women elected to continue treatment with the levonorgestrel-releasing intrauterine system after study completion (77\% compared with $22 \%) .{ }^{15}$

Other advantages of using the levonorgestrel-releasing intrauterine system over progestin therapy include improved adherence (no action required by the user after placement) and the effective contraception that it provides. In a Finnish trial, in women randomly assigned to receive either levonorgestrel-releasing intrauterine system or hysterectomy for treatment of heavy menstrual bleeding, no difference in health-related quality of life was noted in the two treatment groups; at 5 years, $48 \%$ of the levonorgestrel-releasing intrauterine system group continued to use the device and $42 \%$ had undergone hysterectomy. Costs were threefold higher in the hysterectomy group up to 5 years of follow-up. ${ }^{16}$

Although hysterectomy negates the need for contraception, it represents an irrevocable step that some women would prefer to avoid. Similarly, although endometrial ablation limits fertility, women undergoing 
this procedure require effective contraception and any subsequent pregnancy would be at high risk of major obstetric complications. Most of the adverse events reported during our study were mild to moderate in intensity in both groups. These results confirm that the levonorgestrel releasing intrauterine system and medroxyprogesterone acetate have favorable safety profiles and are well-tolerated in women with heavy menstrual bleeding.

\section{Limitations}

Limitation of our study is the small number of cases and short term follow-up. Therefore further longitudinal studies with large sample size should be conducted.

\section{CONCLUSION}

In conclusion, among women with documented idiopathic heavy menstrual bleeding, the levonorgestrelreleasing intrauterine system results in a greater reduction in menstrual blood loss and a higher likelihood of treatment success than treatment with oral medroxyprogesterone acetate. This trial adds to a substantial body of evidence demonstrating the utility of the levonorgestrel-releasing intrauterine system in the treatment of heavy menstrual bleeding.

\section{ACKNOWLEDGMENTS}

Funding: No funding sources

Conflict of interest: None declared

Ethical approval: The study was approved by the Institutional Ethics Committee

\section{REFERENCES}

1. Kjerulff KH, Erickson BA, Langenberg PW. Chronic gynecological conditions reported by US women: Findings from the national health interview survey, 1984 to 1992. Am J Public Health. 1996; 86:195-9.

2. Barnard K, Frayne SM, Skinner KM, Sullivan LM. Health status among women with menstrual symptoms. J Women's Health. 2003;12:911-9.

3. Wu JM, Wechter ME, Geller EJ, Nguyen TV, Visco AG. Hysterectomy rates in the United States, 2003. Obstet Gynecol. 2007;110:1091-5.

4. Whiteman MK, Hillis SD, Jamieson DJ, Morrow B, Podgornik MN, Brett KM, et al. Inpatient hysterectomy surveillance in the United States, 20002004. Am J Obstet Gynecol. 2008;198:34:e1-7.

5. National Collaborating Centre for Women's and Children's Health. Heavy menstrual bleeding Commissioned by the National Institute for Health and Clinical Excellence. 2007. Available http://www.nice.org.uk/nicemedia/pdf/CG44Full Guideline.pdf. Accessed on 28 April, 2020.

6. Crosignani PG, Luciano A, Ray A, Bregqvist A. Subcutaneous depot medroxyprogesterone acetate Vs leuprolide acetate in the treatment of endometriosisassociated pain. Hum Reprod. 2006;21:248-56.

7. Schlaff WD, Carson SA, Luciano A, Ross D, Bergqvist A. Subcutaneous injection of depot medroxyprogesterone acetate compared with leuprolide acetate in the treatment of endometriosisassociated pain. Fertil Steril. 2006;85(2):314-25.

8. Arias RD, Jain JK, Brucker C, Ross D, Ray A. Changes in bleeding patterns with depot medroxyprogesterone acetate subcutaneous injection 104mg. Contraception. 2006;74(3):234-8.

9. Kaunitz AM, Bissonnette F, Monteiro I, Lukkari-Lax E, Muysers C, Jensen JT. Levonorgestrel-releasing intrauterine system or medroxyprogesterone for heavy menstrual bleeding: a randomized controlled trial. Obst Gynecol. 2010;116(3):625-32.

10. Danielsson GK, Schellschmidt I, Apter D. A randomized, phase II study describing the efficacy, bleeding profile, and safety of two low-dose levonorgestrel-releasing intrauterine contraceptive systems and Mirena. Fertil Steril. 2012;97(3):616-22.

11. Hu E, Ikeako LC, Okafor NC. The use of DMPA injectable contraceptive in Enugu Nigeria. Niger $\mathbf{J}$ Med. 2012;21(S):266-71.

12. Uysal A, Taner CE, Mun S, Uysal F, Celimli FH. Use of a levonorgestrel-releasing intrauterine device in the treatment of adenomyosis associated heavy menstrual bleeding. J Pak Med Assoc. 2013;63(11):1349-52.

13. Taru G, Nupur G, Sangeeta G, Pushpa B, Jyoti J, Sushma K. Levonorgestrel intrauterine system (LNG IUS) in menorrahgia: a follow-up study. Open J Obst Gynecol. 2014;2014.

14. Polis RL, Hertweck SP. Treatment options for the adolescent patient experiencing abnormal uterine bleeding. current treatment options in pediatrics. 2016;2(3):184-95.

15. Mejia M, McNicholas C, Madden T, Peipert JF. Association of baseline bleeding pattern on amenorrhea with levonorgestrel intrauterine system use. Contraception. 2016;94(5):556-60.

16. Oroma B, Nwanodi. Progestin intrauterine device versus intramuscular medroxyprogesterone acetate for heavy menstrual bleeding control. Open access J Gynecol Obstet. 2017, 1(1):002.

Cite this article as: Jain S, Mani P. Study of menstrual pattern changes in patients accepting injection Depo- Medroxyprogesterone Acetate versus Levonorgestrel Intrauterine System. Int J Reprod Contracept Obstet Gynecol 2021;10:469-73. 